\title{
Evaluating critical success factors in public - private partnership water supply infrastructure projects
}

\author{
Phuong Van Nguyen ${ }^{1, *}$, Hoa Doan Xuan Trieu ${ }^{1}$, Minh Anh Do $^{1}$, and Anh Tuan Nguyen ${ }^{1}$ \\ ${ }^{1}$ Center For Public Administration, International University, Vietnam National University-HCMC
}

\begin{abstract}
Research background: Public-private partnership (PPP) has been implemented in Vietnam since 1995 in the field of water supply. It is worth noting that not all governments are successful in implementing the PPP policy. According to studies in many countries in the region on the factors affecting the success of a PPP project, there are many similarities. However, differences in politics and administrative systems of each country can lead to changes in the influencing factors, changes in the degree of influence of the above factors on the success of the PPP project.

Purpose of the article: This article aims to identify critical success factors (CSFs) that enable successful project execution, contributing to knowledge for practitioners in assessing the likelihood of success in executing a public-private partnerships PPP water supply project.

Methods: In-depth interviews with PPP specialists in the water supply sector have confirmed the list of CSFs, after which the attributes are weighted to evaluate among different types of PPP by applying the AHP approach. The influences of CSFs were evaluated by data collected using a sample survey of 20 experts involved in the water supply sector and PPP projects in Vietnam. In Vietnam, the study finds seven CSFs affecting the success of PPP projects in the domestic water supply sector, including political environment, commitment of partners, strong consortium, asset quality/social support, national PPP unit, good governance, and project feasibility.

Findings \& Value added: The results reveal that the political environment is CSF that has the strongest impact on the success of the projects. As suggested by AHP, the BOO contract type of a PPP project in Vietnam water supply industry is chosen above the BOT contract.
\end{abstract}

Keywords: public private partnership; critical success factors; water supply

JEL Classification: $K 2$; $C 6$; $H 5$

\footnotetext{
*Corresponding author: nvphuong@hcmiu.edu.vn
} 


\section{Introduction}

Policymakers in industrialized and emerging areas have increasingly embraced public-private partnerships (PPPs) as a groundbreaking procurement strategy for developing public infrastructure (Chou and Pramudawardhani, 2015). Over the last couple of decades, the PPP definition has garnered widespread recognition and has evolved exponentially on a global scale. Global experience has shown that when correctly formulated, PPP may have a variety of benefits. Nevertheless, not all administrations have been effective. Countries that have thoroughly analyzed and investigated the success factors that contribute to the progress of policy execution have reaped significant gains from the resources and benefits associated with this procurement process (Osei-Kyei and Chan, 2015). Conversely, countries with few lessons to draw on have not adequately benefited from implementing the PPP policy.

In the water sector, PPP takes two forms which are service-based models and finance-based. Service-based model leverages the skills and management of the private sector to reduce costs and improve operational efficiency in existing water systems. In contrast, the finance-based approach leverages the private sector's innovative capabilities and capital to develop new water infrastructure with little or no public financial involvement. The type of PPP for a water supply project is determined by the characteristics of the water sector in the host country and its social, economic, and political conditions. The majority of studies found that PPP results often fell short of standards for various factors, including ineffective and inexperienced enforcement (Casarin et al., 2007), lack of government experience, poor contract designs and renegotiations, and sectorrelated barriers (Effah Ameyaw and Chan, 2013).

To deal with the extensive infrastructure plan proposed for the coming years, the Vietnamese government has been seeking alternative methods to relieve its financial burden. As a result, the PPP has become an ideal option favored by both the public and private sectors. PPPs are a reform tool for resolving inefficiency and the absence of dynamism in water supply delivery in developing countries (Ameyaw and Chan, 2016). To cope with the increased number of PPP projects foreseeable in the near future, it requires studying this method's practice in Vietnam. This study describes a set of critical success factors (CSFs) that would ensure successful project implementation and provide a predictive tool to aid implementers in evaluating the possibility of a successful PPP water supply project.

Previous research on critical success factors (CSFs) for PPP projects varies in scope and sector and shows differences in focus and minimal consensus on these factors. Though various empirical studies significantly contribute to our understanding of CSFs for general PPPs, relevant questions are not yet adequately addressed: (1) What are CSFS contributing to the success of PPP water supply projects in Vietnam; (2) Given a set of CSFS, what is the possibility that they would successfully implement a project. Because the CSFs relationships and quantitative impacts on project success have not been addressed in many previous studies, our research focuses on filling this research gap by identifying and evaluating CSFs for water supply projects in Vietnam.

\section{Methods}

\subsection{Identification of CSFs factor for PPP for BOT/BOO contract in water project}

The research begins by identifying a series of CSFs for PPP water projects which was accomplished by using a qualitative method. First, a comprehensive review of water supply PPP projects in Vietnam was undertaken on both active and failed projects to identify CSFs. The identified factors from the case studies were validated through a comprehensive analysis of the literature to determine how well these factors relate to previous literature. We conducted in-depth interviews with experts in the water supply sector to facilitate any previously unknown related success factors. Although it is impossible to include all CSFs due to the variety of PPP modalities 
used in practice, the listed factors were deliberately chosen to address the most critical concerns and serve as consensus-based factors that usually affect the success of water management projects in developing countries. There are 7 CSFs have been defined and finalized.

\subsubsection{Political environment}

The political environment is a vital critical success factor in PPPs. The government ensured that all requisite rights and state approvals for water plant development were obtained on time. One fascinating commitment is the ease with which the scheme was procured in accordance with national policy (Osei-Kyei and Chan, 2017). The political environment includes government (political) commitment, capacity building for local utility staff, competitive tendering (Dulaimi et al., 2010).

\subsubsection{Commitment of partner}

The commitment refers to the dedication and interest of stakeholders in a project (Toor and Ogunlana, 2008), particularly the public client, project team, project sponsor, and project company. This means that all project stakeholders should contribute their best financial and human capital to the project during the project's lifecycle ( $\mathrm{Li}$ et al., 2005). A commitment of partners consists of a strong commitment from project partners, strong and competent public partners, internal coordination within government, and flexible contracts with fair risk allocations.

\subsubsection{Strong consortium}

According to Almarri and Boussabaine (2017), a strong private consortium is an important CSF. The larger the consortium, the more expertise it adds to the project in terms of planning and implementing the most profitable and successful ventures with the least amount of capital outlay. A strong consortium consists of a strong and competent private partner, effective legislative and legal structures, and profitable water supply projects (Ameyaw and Chan, 2016).

\subsubsection{Asset quality and social support}

Asset quality and social comprises quality of water asset and workforce, public acceptance and support, and adequate financing (Ameyaw and Chan, 2016). Meng et al. (2011) clarified that attracting private investors requires a high standard of asset quality as well as workforce. A successful PPP involves understanding and a supportive community. Without social support, the progress of the PPP project can be delayed and can cause the reconsideration of the construction of elements of the project which in turn impacts the success of the project (Almarri and Abuhijleh, 2017; Hall et al., 2005; Li et al., 2005).

\subsubsection{National public-private partnership unit}

National public-private partnership unit consists of PPP policy and implementation unit. The finding indicates the significance of this factor according to the industry practitioners. Fischer et al. (2006) emphasized the importance of PPP task forces in ensuring the effective implementation of PPPs. 


\subsubsection{Good governance}

The impact of a good governance on the success of PPP projects was recorded in Ethiopia (Debela, 2019), Nigeria (Muhammad and Johar, 2019). Inadequate government ability and improper intervention in managing PPP projects can result in project failure as a result of a lack of good governance (Kwak et al., 2009).

\subsubsection{Project technical feasibility}

Project technical feasibility has been emphasised in prior PPP studies on CSFs both in developed and developing countries (Ismail, 2013; Osei-Kyei and Chan, 2015). Kwofie et al. (2016) described accurate project identification and technical feasibility as a remedy for inadequate feasibility.

\subsection{Analytic Hierarchy Process (AHP)}

Following the consultation and a thorough literature review, the completed list of 7 CSFs remained to process to the quantitative phase. The questionnaires, including a detailed explanation of the research goals and guidance about how to complete them, were sent to 20 experts involved in PPP projects in the water supply sector via email.

AHP approach has been applied to analyze the CSFs of PPP water supply projects. AHP is a linear assessment multiple criteria decision making (MCDM) technique that is based on three basic principles: building a hierarchical structure, judging comparatively activities or variables, synthesizing the priorities (Prakash and Barua, 2016). The questionnaire was designed by applying the Saaty's scale proposed by Saaty (1987). This scale uses the value from 1 to 9 to help the participants express their evaluation in detail. The survey requires the participants to evaluate seven CSFs in pairs, which means they will assess each CSFs with other remaining factors. This pairwise comparison allows the research to find out which CSFs are substantial compared to others.

Seven CSFs must be evaluated in addition to two alternatives (BOO, BOT). The main objective of using the AHP approach for this research is to find the weight vector or priority vector. The ranking result or prioritization generated from AHP analysis is the most critical outcome that this study targets. However, when applying the AHP technique, a factor that is needed to be considered is the Consistency Ratio (C.R.) (R. W. Saaty, 1987). The computation of C.R. requires the values of $\lambda_{\max }$ and Consistency Index (CI), as shown in table 1 , and the pairwise matrix comparison using the AHP approach between six alternatives is presented in table 2.

To ensure consistency, Consistency Ratio (C.R.) $\leq 10 \%$. CR is calculated by using the equation:

$$
C R=\frac{C I}{R I}
$$

Equation using to calculate the values of $\lambda_{\max }$ :

$$
\lambda_{\max }=\sum_{i=1}^{n} w_{1} \cdot \sum_{j=1}^{n} a_{i j}
$$

To calculate the Consistency Index (CI), we applied:

$$
C I=\frac{\lambda_{\max }-n}{n-1}
$$

Table 1. Random Indices (R.I.) for pairwise comparison matrix (R. W. Saaty, 1987):

\begin{tabular}{llllllllll}
\hline $\mathrm{n}$ & 1 & 2 & 3 & 4 & 5 & 6 & $\mathbf{7}$ & 8 & 9 \\
\hline $\mathrm{RI}$ & 0.00 & 0.00 & 0.58 & 0.90 & 1.12 & 1.24 & $\mathbf{1 . 3 2}$ & 1.41 & 1.45 \\
\hline
\end{tabular}


Table 2. Matrix table of Pairwise Comparisons for seven alternatives:

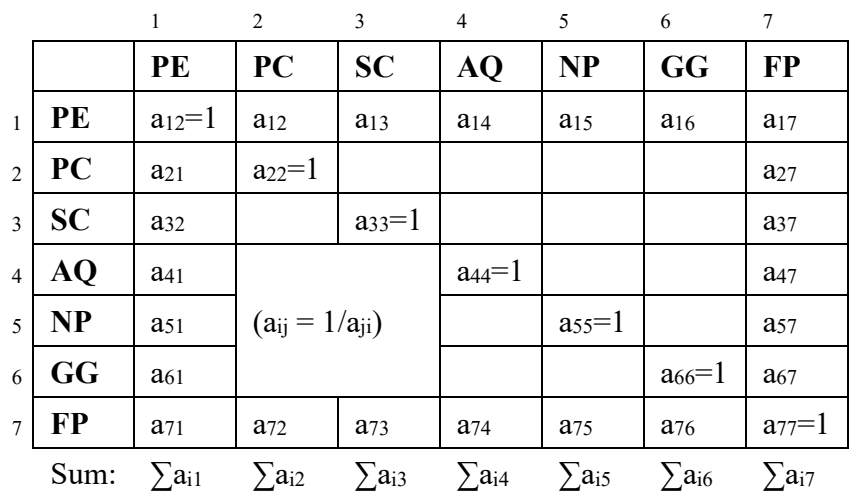

\section{Results}

\subsection{The influences of the CSFs for the BOO contract}

As data collecting from 20 experts in PPP project in the water supply sector, the Analytic Hierarchy Process is applied to weigh the priorities of seven CSFs influencing the success of a PPP water supply project for the BOO contract. The matrix table is presented below. The matrix results are necessary for the calculation of relative weights.

Table 3. Matrix table for CSFs priority for BOO contract

\begin{tabular}{|c|c|c|c|c|c|c|c|c|}
\hline & & $\underline{D}$ & U & Un & $\stackrel{O}{<}$ & $\hat{\mathbf{z}}$ & ৩ & 足 \\
\hline & & 1 & 2 & 3 & 4 & 5 & 6 & 7 \\
\hline PE & 1 & 1 & $15 / 9$ & 3 & 3 & $22 / 3$ & $23 / 5$ & $13 / 5$ \\
\hline $\mathrm{PC}$ & 2 & $2 / 3$ & 1 & $12 / 3$ & $22 / 3$ & 2 & $22 / 5$ & $11 / 7$ \\
\hline $\mathrm{SC}$ & 3 & $1 / 3$ & $3 / 5$ & 1 & $15 / 6$ & $13 / 4$ & $11 / 2$ & $7 / 8$ \\
\hline AQ & 4 & $1 / 3$ & $3 / 8$ & $1 / 2$ & 1 & $11 / 4$ & $11 / 8$ & $2 / 3$ \\
\hline NP & 5 & $3 / 8$ & $1 / 2$ & $4 / 7$ & $4 / 5$ & 1 & $15 / 9$ & $2 / 3$ \\
\hline GG & 6 & $2 / 5$ & $2 / 5$ & $2 / 3$ & $8 / 9$ & $2 / 3$ & 1 & $4 / 5$ \\
\hline FP & 7 & $5 / 8$ & $7 / 8$ & $11 / 7$ & $14 / 7$ & $14 / 9$ & $11 / 4$ & 1 \\
\hline
\end{tabular}

As shown in the table, the political climate (PE) contributes the most to the relative weight value of all alternatives, accounting for $27 \%$ of the total. The commitment of partner (PC) follows with a proportional weight of about $19.2 \%$. The project technical feasibility (FP) is ranked third with the weight standing at $14.2 \%$. The fourth and fifth places in the ranking table are taken by the strong consortium (SC) and the national public-private collaboration team (NP), respectively. While SC represents 12.9 percent of the total, national public-private partnership unit (NP) accounts for 9.4 percent. Asset quality and social support weights approximately $8.8 \%$. With an 8.5 percent weighting, good governance $(\mathrm{GG})$ is deemed the least significant CSF. The error indices of seven CSFs vary from $1.6 \%$ to $5.7 \%$, which is considered to be low. Thus, the result of prioritization is accepted. The CR equals to 0.006 , which is less than $10 \%$ (Saaty, 1987; Saaty, 2002) so the findings meet the threshold. 
Table 4. The ranking order of CSFs for BOO contract from AHP

\begin{tabular}{ccccc}
\hline Criterion & Comment & Rank & aвоO & $\Delta(+/-)$ \\
\hline PE & Political environment & 1 & $27,0 \%$ & $5.7 \%$ \\
PC & Commitment of partner & 2 & $19.2 \%$ & $2.4 \%$ \\
FP & Project technical feasibility & 3 & $14.2 \%$ & $2.0 \%$ \\
SC & Strong consortium & 4 & $12.9 \%$ & $2.6 \%$ \\
NP & National PPP unit & 5 & $9.4 \%$ & $2.0 \%$ \\
AQ & Asset quality and social support & 6 & $8.8 \%$ & $1.6 \%$ \\
GG & Good governance & 7 & $8.5 \%$ & $1.7 \%$ \\
\hline
\end{tabular}

\subsection{The influences of the CSFs for the BOT contract}

Regarding BOT contract, the CSFs priority weights are estimated according to data collected from the survey of 20 experts in PPP projects in the water supply sector. The matrix table for CSFs priority for the BOT contract is presented below.

Table 5. Matrix table for CSFs priority for the BOT contract

\begin{tabular}{|c|c|c|c|c|c|c|c|c|}
\hline & & $\sigma_{1}$ & ${ }_{2}-$ & 3 & $4_{4}^{-}$ & $r_{5}$ & $-\frac{-}{6}$ & 7 \\
\hline PE & 1 & 1 & $11 / 5$ & $21 / 8$ & $22 / 5$ & $21 / 7$ & $25 / 7$ & $11 / 8$ \\
\hline PC & 2 & $5 / 6$ & 1 & $25 / 8$ & $31 / 9$ & $22 / 9$ & $21 / 7$ & 1 \\
\hline $\mathrm{SC}$ & 3 & $1 / 2$ & $3 / 8$ & 1 & $11 / 3$ & 1 & $11 / 3$ & $1 / 2$ \\
\hline AQ & 4 & $2 / 5$ & $1 / 3$ & $3 / 4$ & 1 & 1 & 1 & $1 / 2$ \\
\hline NP & 5 & $1 / 2$ & $4 / 9$ & 1 & 1 & 1 & $11 / 2$ & $1 / 2$ \\
\hline GG & 6 & $3 / 8$ & $1 / 2$ & $3 / 4$ & 1 & $2 / 3$ & 1 & $3 / 5$ \\
\hline FP & 7 & $8 / 9$ & 1 & $18 / 9$ & 2 & 2 & $15 / 7$ & 1 \\
\hline
\end{tabular}

As shown in table 6, political environment (PE) has the greatest influence on the weight value of all alternatives, accounting for $22.3 \%$. The commitment of partner (PC) is ranked second, with a weighting of about $21.9 \%$. The project technical feasibility (FP) with a weight of $14.2 \%$ is rated as the third important factor contributing to the success of the project. The national public-private unit (NP) weights for $10.2 \%$; meanwhile, the strong consortium (SC) accounts for $10.1 \%$ of the total. The NP and SC are ranked fourth and fifth, respectively. Asset quality and social support (AQ) account for about $8.7 \%$ of the total weight. With a weighting of $8.6 \%$, good governance is considered the least essential CSF. The error indices of seven CSFs vary from $1.1 \%$ to $3.6 \%$, which is considered to be low. Thus, the result of prioritization is accepted.

Table 6. The ranking order of CSFs for BOT contract from the AHP

\begin{tabular}{ccccc}
\hline Criterion & Comment & Rank & авот & $\Delta(+/-)$ \\
\hline PE & Political environment & 1 & $22.3 \%$ & $1.9 \%$ \\
PC & Commitment of partner & 2 & $21.9 \%$ & $3.6 \%$ \\
FP & Project technical feasibility & 3 & $18.4 \%$ & $2.0 \%$ \\
NP & National PPP unit & 4 & $10.2 \%$ & $1.2 \%$ \\
SC & Strong consortium & 5 & $10.1 \%$ & $1.1 \%$ \\
AQ & Asset quality and social support & 6 & $8.7 \%$ & $1.1 \%$ \\
GG & Good governance & 7 & $8.6 \%$ & $1.3 \%$ \\
\hline
\end{tabular}




\subsection{The influences of the CSFs for the BOT/BOO contract}

The AHP approach is used to weigh the values of seven CSFs impacting the success of a PPP water supply project for the $\mathrm{BOO} / \mathrm{BOT}$ contract based on data collected from 20 experts in the water supply industry. The matrix table is shown below.

Table 3. Matrix table for CSFs value for the $\mathrm{BOO} / \mathrm{BOT}$ contract

\begin{tabular}{|c|c|c|c|c|}
\hline PE & & $\mathrm{BOO}$ & BOT & V \\
\hline & & 1 & 2 & \\
\hline $\mathrm{BOO}$ & 1 & 1 & $14 / 7$ & $61,07 \%$ \\
\hline BOT & 2 & $2 / 3$ & 1 & $38,93 \%$ \\
\hline PC & & $\mathrm{BOO}$ & BOT & $\mathbf{V}$ \\
\hline BOO & 1 & $\begin{array}{l}1 \\
1\end{array}$ & $\begin{array}{c}2 \\
11 / 2\end{array}$ & $59,31 \%$ \\
\hline BOT & 2 & $2 / 3$ & 1 & $40,69 \%$ \\
\hline SC & & $\mathrm{BOO}$ & BOT & $\mathbf{V}$ \\
\hline $\begin{array}{l}\text { BOO } \\
\text { BOT }\end{array}$ & $\begin{array}{l}1 \\
2\end{array}$ & $\begin{array}{c}1 \\
1 \\
4 / 9\end{array}$ & $\begin{array}{c}2 \\
21 / 5 \\
1\end{array}$ & $\begin{array}{l}68,76 \% \\
31,24 \%\end{array}$ \\
\hline $\mathbf{A Q}$ & & $\mathrm{BOO}$ & BOT & $\mathrm{V}$ \\
\hline $\begin{array}{l}\text { BOO } \\
\text { BOT }\end{array}$ & 1 & $\begin{array}{c}1 \\
1 \\
2 / 3\end{array}$ & $\begin{array}{c}2 \\
11 / 2 \\
1\end{array}$ & $\begin{array}{l}60,51 \% \\
39,49 \%\end{array}$ \\
\hline
\end{tabular}

\begin{tabular}{c|cccc}
\hline NP & & BOO & BOT & V \\
\hline & & 1 & 2 & \\
\hline BOO & 1 & 1 & $12 / 9$ & $54,86 \%$ \\
\hline BOT & 2 & $5 / 6$ & 1 & $45,14 \%$ \\
\hline \multicolumn{5}{|c}{} \\
\hline CG & BOO & BOT & $\mathbf{V}$ \\
\hline & 1 & 2 \\
BOO & 1 & 1 & $28 / 9$ & $74,34 \%$ \\
BOT & 2 & $1 / 3$ & 1 & $25,66 \%$ \\
\hline \multicolumn{5}{|c}{} \\
\hline FP & \multicolumn{5}{|c}{ BOO } & BOT & $\mathbf{V}$ \\
\hline & \multicolumn{5}{c}{2} \\
BOO & 1 & 1 & $22 / 7$ & $69,54 \%$ \\
BOT & 2 & $4 / 9$ & 1 & $30,46 \%$ \\
\hline
\end{tabular}

\subsection{The synthesized performances of $\mathrm{BOO}$ and BOT contract}

The synthesized performance of each type of PPP contract is calculated as:

$$
P_{i}=\sum_{j=1} a_{i j} v_{i j}
$$

The BOO contract performance based on the weights and values of CSFs(j):

$$
P_{B O o}=\sum_{j=1}^{7} a_{B O o j} v_{B O o j}=63.42 \%
$$

The BOO contract performance based on the weights and values of CSFs(j):

$$
P_{B O T}=\sum_{j=1}^{7} a_{\text {BOTj }} v_{\text {BOTj }}=36.53 \%
$$

Results suggest that the BOO contract option has a performance of $63.4 \%$, which is 1.74 times the performance of the BOT contract option (36.5\%). With such a significant difference, the authors believe that opting for the BOO contract offers more benefits. Indeed, for the BOO model, the government merely has to approve a good policy, and the private sector would invest heavily in the project if it is possible. Furthermore, the form of BOO does not need the transfer of assets (of the project) once the operating time finishes; hence it is a kind of long-term ownership. The project in this form is more appealing to investors due to its "ownership" aspect, demonstrating more advantageous capital mobilization. 


\section{Discussion}

Seven CSFs examined have impact on the effectiveness of two forms of PPP contracts: BOO and BOT. Each CSF has a varying degree of influence on each form of contract. The level of impact of the factors on the two types of contract BOO and BOT are divided into two groups: (i) Group with above-average impact and (ii) The group has below average impact. The three most influenced key factors impacting the success of PPP ventures in water supply for both BOO and BOT contracts are political environment, commitment of partner, and project technical feasibility.

The political environment is the CSF that has the highest impact on PPP project success in developing countries. An unstable political environment may result in termination, poor governance, insecurity, and lack of transparency and accountability of the government. Ensuring strong political support by governments before embarking PPP projects protects the private sector's interest and maintains the sustainability of the infrastructure development (Wibowo and Alfen, 2014). The commitment of partners ranks second and has a significant impact on the success of the PPP water supply projects. All project stakeholders should be willing to commit their best financial and human resources to the project throughout its lifecycle (Antwi-Afari et al., 2018). The technical feasibility of the project has a great impact on the success of the PPP project in the water supply sector. The primary source of revenue from water supply projects comes from the volume of water supply to customers multiplied by the unit price of water. Clean water is an asset that cannot be utilized over the demand because the supply at each stage during the project's life cycle is set, and there is no basis for rapid expansion. Besides, the water unit price is regulated and controlled. Therefore, for the project to succeed, it is necessary to optimize the technique and achieve investment efficiency, the project's feasibility.

In the group with below-average impacts, the analysis shows that up to 3 of 7 factors impact less than $10 \%$ on the success of PPP projects in the water supply sector. We do not exclude these factors to reallocate the impact of the more influential factors because we want to keep the diversity of factors affecting the success of the PPP project. This also reflects the multidimensionality of Vietnam's economy and society. Good governance is evaluated to have the most negligible influence on the success of a PPP project under both forms of contract; meanwhile, it was considered to have the most decisive impact on the PPP projects in China and Indonesia.

Regarding the contract forms, the political environment has the most substantial influence on the success of the project. It is calculated that the fluctuation amplitude of this factor is also the largest $(+/-5,7 \%)$. It proves that although there is consensus on the impact, experts have different views on the level of influence of the political environment factor. The remaining factors have smaller fluctuations from $1.6 \%-2.4 \%$, showing that experts are quite focused when assessing the influence of each of these factors on the success of the BOO contract. There is a consistency of the degree of influence of CSFs on the success of the project in the form of BOT contract. The group with above-average impact has a similar weight, which means that experts believe that these three factors are equally important for the BOT form of contract.

The result of this study found that BOO contract form is preferred to the BOT. For a successful $\mathrm{BOO} / \mathrm{PPP}$ project, the most important factor is the political environment, followed by commitment of partner, project feasibility. This is similar to the previous finding conducted in the UAE, China, and Hong Kong. For each PPP water supply project, it is necessary to prescribe specific criteria or requirements to facilitate the management, investment monitoring, investor selection. The overall success of a PPP project in the water supply sector will improve infrastructure to help increase national competitiveness, contributing to economic and social development. 


\section{Conclusion}

Through previous studies, surveys and analysis, the results of this study confirmed that 07 CSFs are affecting the success of PPP projects in the water supply sector in Vietnam, namely: Political environment, Comment of partner, Strong consortium, Quality of assets/ social support, National PPP unit, Good governance, and Project feasibility. The degree of influence of these factors is different and depends on whether the PPP contract is BOO or BOT. The level of influence is divided into two groups: the group with moderate and above-average impact, including political environment, commitment of partners, project feasibility. The factor that has the most influence on the success of PPP water supply project is the political environment. The group with belowaverage impact are the remaining factors. The BOO contract form of the PPP project in the water supply sector in Vietnam is the preferred form compared to the BOT contract.

\section{Acknowledgments}

This research was funded by International University, VNU-HCM, grant number SV2020-PM03.

\section{References}

1. Almarri, K., \& Abuhijleh, B. (2017). A qualitative study for developing a framework for implementing public-private partnerships in developing countries. Journal of Facilities Management, 15(2), 170-189.

2. Almarri, K., \& Boussabaine, H. (2017). Interdependency of the critical success factors and ex-post performance indicators of PPP projects. Built Environment Project and Asset Management, 7(5), 546-556.

3. Ameyaw, E. E., \& P.C. Chan, A. (2016). Critical success factors for public-private partnership in water supply projects. Facilities, 34(3-4), 124-160.

4. Antwi-Afari, M. F., Li, H., Pärn, E. A., \& Edwards, D. J. (2018). Critical success factors for implementing building information modelling (BIM): A longitudinal review. In Automation in Construction 91, pp. 100-110.

5. Casarin, A. A., Delfino, J. A., \& Delfino, M. E. (2007). Failures in water reform: Lessons from the Buenos Aires's concession. Utilities Policy, 15(4), 234-247.

6. Chou, J. S., \& Pramudawardhani, D. (2015). Cross-country comparisons of key drivers, critical success factors and risk allocation for public-private partnership projects. International Journal of Project Management, 33(5), 1136-1150.

7. Debela, G. Y. (2019). Critical success factors (CSFs) of public-private partnership (PPP) road projects in Ethiopia. International Journal of Construction Management.

8. Dulaimi, M. F., Alhashemi, M., Ling, F. Y. Y., \& Kumaraswamy, M. (2010). The execution of public-private partnership projects in the UAE. Construction Management and Economics, 28(4), 393-402.

9. Effah Ameyaw, E., \& Chan, A. P. C. (2013). Identifying public-private partnership (PPP) risks in managing water supply projects in Ghana. Journal of Facilities Management, 11(2), 152-182.

10. Fischer, K., Jungbecker, A., \& Alfen, H. W. (2006). The emergence of PPP Task Forces and their influence on project delivery in Germany. International Journal of Project Management, 24(7), 539-547. 
11. Hall, D., Lobina, E., \& de la Motte, R. (2005). Public resistance to privatisation in water and energy. Development in Practice, 15(3-4), 286-301.

12. Ismail, S. (2013). Critical success factors of public private partnership (PPP) implementation in Malaysia. Asia-Pacific Journal of Business Administration, 5(1), 6-19.

13. Kwak, Y. H., Chih, Y., \& Ibbs, C. W. (2009). Towards a comprehensive understanding of public private partnerships for infrastructure development. In California Management Review 51(2), pp. 51-78).

14. Li, B., Akintoye, A., Edwards, P. J., \& Hardcastle, C. (2005). Perceptions of positive and negative factors influencing the attractiveness of PPP/PFI procurement for construction projects in the UK: Findings from a questionnaire survey. In Engineering, Construction and Architectural Management 12(2), pp. 125-148.

15. Meng, X., Zhao, Q., \& Shen, Q. (2011). Critical Success Factors for Transfer-OperateTransfer Urban Water Supply Projects in China. Journal of Management in Engineering, 27(4), 243-251.

16. Muhammad, Z., \& Johar, F. (2019). Critical success factors of public-private partnership projects: a comparative analysis of the housing sector between Malaysia and Nigeria. International Journal of Construction Management, 19(3), 257-269.

17. Osei-Kyei, R., \& Chan, A. P. C. (2015). Review of studies on the critical success factors for public-private partnership (PPP) projects from 1990 to 2013. International Journal of Project Management, 33(6), 1335-1346.

18. Osei-Kyei, R., \& Chan, A. P. C. (2017). Implementing public-private partnership (PPP) policy for public construction projects in Ghana: critical success factors and policy implications. International Journal of Construction Management, 17(2), 113-123.

19. Prakash, C., \& Barua, M. K. (2016). An analysis of integrated robust hybrid model for thirdparty reverse logistics partner selection under fuzzy environment. Resources, Conservation and Recycling, 108, 63-81.

20. Saaty, R. W. (1987). The analytic hierarchy process-what it is and how it is used. Mathematical Modelling, 9(3-5), 161-176.

21. Saaty, T. L. (2002). Decision making with the Analytic Hierarchy Process. Scientia Iranica, 9(3), 215-229.

22. Toor, S. ur R., \& Ogunlana, S. O. (2008). Critical COMs of success in large-scale construction projects: Evidence from Thailand construction industry. International Journal of Project Management, 26(4), 420-430.

23. Wibowo, A., \& Alfen, H. W. (2014). Identifying macro-environmental critical success factors and key areas for improvement to promote public-private partnerships in infrastructure: Indonesia's perspective. In Engineering, Construction and Architectural Management, 21(4), pp. 383-402. 